\title{
A CLOSED-FORM BUCKLING FORMULA FOR OPEN-COILED AND PROPERLY SUPPORTED CIRCULAR-BAR HELICAL SPRINGS
}

\author{
YILDIRIM Vebil ${ }^{1}$ \\ ${ }^{1}$ Cukurova University, Department of Mechanical Engineering, 01330, Adana, Turkey, \\ e-mail:vebil@cu.edu.tr
}

\begin{abstract}
As a continuation of the author's previous studies on the buckling analysis of helical springs, a closedform formula having been obtained with the help of the artificial neural network (ANN) is proposed and discussed in detail for the first time for a cylindrical close/open-coiled helical spring with fixed ends and having a solid circular section. As far as the author knows there is no such a formula in the open-literature to consider the effects of all stress resultants (torsional and bending moments, axial and shearing forces), large helix pitch angles together with the axial and shear deformations on the buckled state. The present formula may be used in a wide range of the total number of active turns, the ratio of the free axial length to the mean helix diameter, and the spring index. It is yet again revealed that it is not appropriate to use the elementary theory to determine the critical buckling loads for open-coiled springs. The present formula may allow the deeper understanding of spring buckling mechanism and to be used directly and safely in the design processes of such closely/open-coiled springs.
\end{abstract}

KEYWORDS: stability of springs, buckling loads, closed-form formula, helical spring, open-coiled

\section{Introduction}

A helical spring is an essential structural type for miscellaneous mechanisms [1-5]. It has, therefore, great practical importance from the engineering point of view [6-58]. The first investigations were related to the static response of cylindrical helical springs [6-42]. Haringx [6], Ancker and Goodier [7-9], and Wahl [10] put forward the basis of analytical mechanics of springs. Nagaya et al. [15] also presented design formulae for elliptical cross-sections of helical springs. The complete governing equations of initially twisted elastic space rods made of laminated composite materials are presented by Yildırım [18]. Later, Yu et al. [24] considered the warping of naturally curved and twisted beams with general cross-sectional shapes. Dym [26], first time in the literature, derived the spring rate of a coiled cylindrical extensional helical spring with solid circular wire under an axial force and axially directed torque by a consistent application of Castigliano's second theorem. Dym [26] also presented a common notion about the effects of each stress resultants on the deformation of the spring. Y1ldirım [31] proposed closed form formulas for both close-coiled and open-coiled cylindrical helical compression springs having arbitrarily doubly-symmetric cross-sections by applying Castigliano's first theorem and by considering the whole effects of all stress resultants namely torsional and bending moments and the shearing and axial forces on the tip deflection. Gzal et al. [35] determined analytically the stress distribution in elliptical cross-section of helical springs with small helix angles under axial static loads. They validated their results by finite element analysis and an experimental study conducted on an actual automotive valve spring. Recently, Kobelev [42], presented an advanced treatise of the mechanics of springs with focus on the springs for automotive industry by demonstrating new and original results for the optimization of helical springs. Along with the above analytical studies, some numerical methods such as the finite element method [14, 19, 21-22, 32-36, 41], the transfer matrix method [16], the stiffness matrix 
method [16, 20], and the complementary functions method [17] are also employed for the static analysis of cylindrical helical springs. Unfortunately, the number of experimental studies on helical springs have been still very limited [27, 30, 35, 43-44].

Buckling is one of the substantial failure phenomenon should be considered for helical springs having larger free axial length and improper end conditions [43-58] as well as slender structures. The general consent to prevent the buckling of a spring subjected to a compressive force is, therefore, to restrict to the deflection of the spring or the free axial length of the spring (Fig.1).

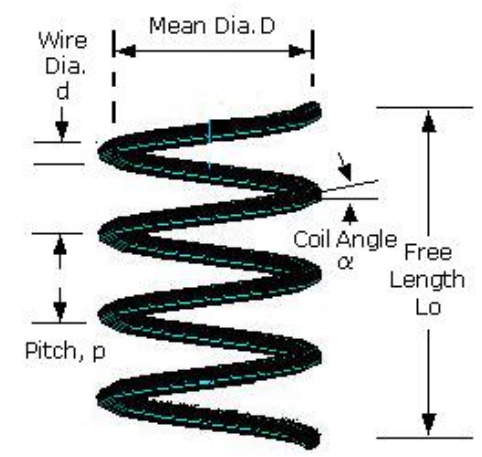

Fig. 1 Geometry of a cylindrical helical spring

A comprehensive buckling behavior of such springs are rarely tackled due to the computational complexity of the main problem [45-58]. By reason of just the geometry of a helix (Fig. 1), a helical spring is to be governed by coupled differential equations even for the simplest problem. In static problems, the governing equation of a helical spring, indeed, consists of a single twelve order ordinary differential equation for a boundary value problem (BVP) or a set of twelve ordinary differential equations with first degree for an initial value problem (IVP) $[18,45,50-58]$. When the buckling is considered, additional terms should be included into the governing equations [56]. The open literature also covers some studies related to the helical springs which considers uncoupled differential equations obtained under certain ad-hoc assumptions.

The buckling behaviour of helical springs with large helix pitch angles were handled numerically in a few works by employing the finite element method [47-49], the transfer matrix method [45, 50-56, 58], and the stiffness matrix method [57]. Those studies revealed that Haringx's [1] formula gives accurate results only when the helical spring has a small helix pitch angle, in other words, when the helix angle is usually less than 10 degrees. In conclusion, the elementary theory may give acceptable results for merely closely-coiled helical springs. Chassie et al. [52] also presented some reliable buckling charts to be used in the design stage of cylindrical helical isotropic compression springs with clamped ends and with circular sections. The buckled state deformation was computed in [45-52] by omitting the contribution of the shearing and axial forces, and bending moments. As understood in [18] and [54, 56, 58], the bending moment, the shearing and axial forces may considerably affect the tip deflection as well as the torsional moment especially when the open-coiled springs are concerned or the spring having small spring index is concerned. A governing buckling equation set which also covers the effect of shearing force on the buckled deformation was offered by Yildirım [56] for a compression spring having doubly symmetric solid sections as a first time in the open literature.

Patil et. al. [43] experimentally showed that Haringx's results become poor for values of helix pitch angles which are around ten degrees, and significant deviations from the elementary theory occur at small number of turns or at helix pitch angles around $10^{\circ}$. 
Ibrikci et al [55] explained the use of artificial neural networks (ANN) to perfectly predict the critical buckling loads of cylindrical isotropic helical spring with fixed ends, with circular sections, and with large helix pitch angles. The training network consists of about 5000 epochs (3662 patterns for the training data and 1305 patterns for the questioning set) in the ANN analysis was acquired numerically based on the transfer matrix method [53] by using the governing equation set recommended by [56] in this study. That is the training network in ANN analysis consists of about accurate 5000 epochs each of which was obtained by solving a numerical initial value problem (IVP) of a differential equation set consisting twelve first order differential equation. The maximum relative error was, therefore, found mostly far less than $5 \%$. The detailed knowledge related to the applied ANN procedure may be found in Ibrikci et al.'s [55] study except the buckling formula which is to be presented and discussed in details in the present study.

It is worth noting that the training data set consists of the inputs which are assumed to be in the following ranges (Fig. 1): $C=D / d=4-12, n=$ number of activeturns $=5-30$, and $L_{o} / D=5-16$. As is well known, most springs used in engineering have those parameters within the assumed ranges having physical meaning. After machine learning by ANN, the range of the possible theoretical inputs are extended to the ranges $C=0-60, n=0-80$, and $L_{o} / D=0-70$. In conclusion, the present formula may be safely used to predict accurately the buckling loads of such springs.

\section{Elementary Buckling Formulas}

By using a rod-model approximation, as a pioneering investigator Haringx [6] offered a closed-form buckling formula for cylindrical helical springs. Those formulas are also studied in a detailed manner in [10]. Denoting the helix mean diameter by $D=2 R$, the critical tip deflection by $\delta_{c r}$ which corresponds to the critical buckling load, $P_{c r}$, the following conditions are presented in $[6,10]$ for the buckling criteria of a close-coiled spring with solid circular section (Fig. 1).

$$
\begin{aligned}
& \left.\left(\frac{\delta_{c r}}{L_{0}}\right)_{\text {Fixed-Guided }}=0.8125\left[1-\sqrt{1-6.87\left(\frac{D}{L_{O}}\right.}\right)^{2}\right] \\
& \left(\frac{\delta_{c r}}{L_{0}}\right)_{\text {Fixed-Free }}=0.8125\left[1-\sqrt{1-6.87\left(\frac{D}{2 L_{O}}\right)^{2}}\right] \\
& \left.\left(\frac{\delta_{c r}}{L_{0}}\right)_{\text {Fixed-Fixed }}=0.8125\left[1-\sqrt{1-6.87\left(\frac{2 D}{L_{O}}\right.}\right)^{2}\right]
\end{aligned}
$$

where $L_{0} / D=\pi n \tan \alpha$ and $n$ is the total number of active turns. According to the above formulas the buckling does not occur in a spring with fixed-fixed ends, viz., in a spring supported between flat parallel surfaces when $L_{o} / D<5.242$ (Fig. 2). In other words, if $L_{o} / D>5.242$ the spring will most likely buckle under any compressive axial force. Similarly those bounds are determined as $L_{o} / D<2.621$ for fixed-guided ends, $L_{o} / D<1.31$ for fixedfree ends. 


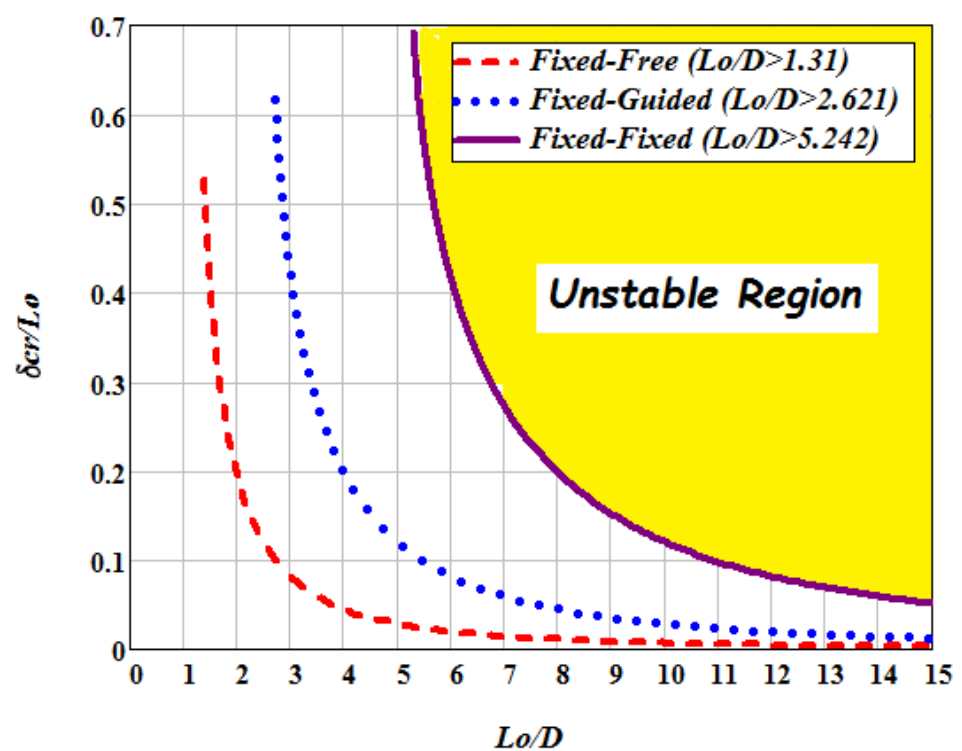

Fig. 2 Wahl's [10] buckling charts for cylindrical helical springs with circular section

In Eqs. (1), the axial critical total tip deflection, $\delta_{c r}$, is computed by using Wahl's [10] classical formula, which may be used for simply close-coiled springs having small helix pitch angles and does not observe the additional effects of both the bending moment and the shearing and axial forces on the tip deflection of the spring [31].

$$
\delta_{c r}^{W a h l}=P_{c r} \frac{8 D^{3} n}{G D^{4}}
$$

As a common opinion, a compression spring whose free length is more than four times its mean diameter is assumed to be necessary to be checked for the buckling phenomenon. In practical applications, the following criteria for absolute stability which is in the simplest combined form of Eqs. (1) and (2) is also frequently used.

$$
L_{o}<\left(\pi D / \xi_{\text {end }}\right) \sqrt{\frac{2(E-G)}{2 G+E}}
$$

where $E$ and $G$ are Young's and shear moduli of the wire material, respectively. In Eq. (3), $\xi_{\text {end }}$ is referred as the end-condition constant or simply end-constant.

$$
\xi_{\text {end }}^{\text {fixed }- \text { fixed }}=0.5, \quad \xi_{\text {end }}^{\text {fixed }- \text { guided }}=1, \quad \xi_{\text {end }}^{\text {fixed }- \text { free }}=2
$$

If the wire material is chosen as a conventional steel material, Eq. (4) may be simplified as

$$
L_{o}^{\text {Steel }}<2.63 D / \xi_{\text {end }}
$$

As $L_{0}$ of a compression spring increases in proportion to its diameter, viz., as the spring becomes more slender, it can be buckle under a compressive axial force. The likelihood of buckling depends upon the maximum load or deflection.

\section{The Present Proposed Buckling Formula}

A spring with fixed-fixed ends is considered as properly guided, viz., as the squared and ground ends are on rigid parallel surfaces perpendicular to the spring's axis. In the present study, it is assumed that the spring end conditions are proper to evenly distribute the load all along the circumference of the coil. Denoting the helix index by $C=D / d$, the critical buckling load is achieved to the following with the help of the ANN analysis in which a three- 
layer (input/hidden/output layers) BP (Back Propagation) network is used as a machine learning ANN method [55].

$$
P_{c r}=\frac{1}{\left(1+e^{-\lambda}\right)} \frac{\pi E d^{4} \cos ^{2} \alpha}{16 D^{2}}=\bar{P}_{c r} \frac{\pi E d^{4} \cos ^{2} \alpha}{16 D^{2}}
$$

where

$$
\lambda=\sum_{i=1}^{i=9} a_{i}
$$

and

$$
\begin{aligned}
& a_{1}=\frac{52.725}{e^{\left(0.0060207039 C+1.579962418 \frac{L_{o}}{D}+0.38393 n-4.2246\right)}+1} \\
& a_{2}=-\frac{54.0024}{e^{\left(-0.0000021986 C-0.0086324461 \frac{L_{o}}{D}-0.003400875 n+1.8442\right)}+1} \\
& a_{3}=-\frac{1.3161}{e^{\left(-0.0001718844 C+0.060753935 \frac{L_{o}}{D}-0.593805 n+0.92015\right)}+1} \\
& a_{4}=\frac{68.6212}{e^{\left(-0.0000688554 C-0.0140317797 \frac{L_{o}}{D}+0.11139875 n+3.5437\right)}+1} \\
& a_{5}=\frac{52.0485}{e^{\left(-0.0005457925 C+0.015181696 \frac{L_{o}}{D}-0.11204875 n-13.1991\right)}+1} \\
& a_{6}=\frac{35.8444}{e^{\left(0.726020175 C+1.287061717 \frac{L_{o}}{D}+0.0161975 n-2.4691\right)}+1} \\
& a_{7}=\frac{65.082}{e^{\left(0.002510502 C+2.362741467 \frac{L_{o}}{D}-0.000141625 n-6.7766\right)}+1} \\
& a_{8}=\frac{96.2904}{e^{\left(-0.0001024655 C-0.322546735 \frac{L_{o}}{D}-0.00458575 n-2.959\right)}+1} \\
& a_{9}=49.3606
\end{aligned}
$$

In Eq. (6-8), $\bar{P}_{c r}$ is the dimensionless critical buckling load and it is a kind of Sigmoid function (squashing function) with three parameters. In ANN, it has been chosen as an activation function to squeeze the outputs. As stated before $a_{i} \mathrm{~s}$ are determined by using accurately computed training network for about 5000 epochs. BP learns by iteratively processing a set of training examples. When a BP network is cycled, an input example is propagated forward to the output through the intervening input-to-hidden and hidden-to-output weights [55].

The present formula may be used in a wide range of the total number of active turns, the ratio of the free axial length to the mean helix diameter, and the spring index. It is yet again revealed that it is not appropriate to use the elementary theory to determine the critical buckling loads for open-coiled springs. The present formula may allow the deeper understanding of spring buckling mechanism and to be used directly and safely in the design processes of such closely/open-coiled springs. 
The sketch of the graph of a typical Sigmoid function is shown in Fig. 3. By considering this graph it may be concluded that, if $\overline{\boldsymbol{P}}_{c r}$ approaches the unit, the buckling probably will not occur. The final decision is made after checking the results by considering the material and the geometry of the spring. For instance, if the corresponding buckling deflection is greater than the difference between the free axial length of the spring and the solid length of the spring, $\left(L_{o}-L_{s}\right)$, the situation becomes physically meaningless. The spring will, therefore, not be buckled under this critical load. As it is known, when the compression spring is compressed until the coils come in contact with each other, then the spring is said to be solid. The solid length of a spring is simply the product of the total number of coils and the diameter of the wire, $\left(L_{s}=n d\right)$.

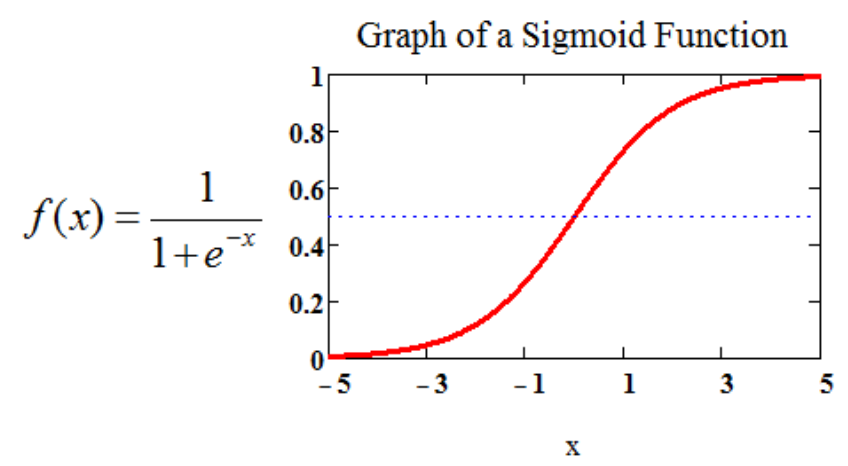

Fig. 3 A graph of a typical Sigmoid function

Y1ldırım [31] offered the following closed-form formula for the analytically determination of the global tip deflection of helical springs with solid circular section.

$$
\delta=\frac{4 n P R \cos \alpha}{d^{4} G(1+v)}\left(-d^{2}+\left(d^{2}+16 R^{2}\right) \sec ^{2} \alpha+2 d^{2}(1+v) k_{T}+16 R^{2} v\right)
$$

where $\alpha$ is the helix pitch angle, $k_{T}$ is the reciprocal of Timoshenko's shear correction factor, $d$ is the helix wire diameter, $v$ is Poisson's ratio of the wire material, and $R=D / 2$ is the mean radius of the helix. Eq. (9) includes the whole effects of the torsional moment, bending moment, axial force and shearing force on the tip deflection. After determining the critical buckling load at which the spring will buckle from the present formula in Eq. (6), corresponding true tip deflection should be determined using Eq. (9) by considering the helix pitch angle of the original spring.

Cowper [59] recommended the following reciprocal of shear correction factor for solid circles in terms of Poisson's ratio.

$$
k_{T}^{\text {Cowper }}=\frac{7+6 v}{6(1+v)}
$$

For practical use, $k_{T}^{\text {SolidCircle }}=1.1$ may be preferred [60]. Apart from those, the definition of the free axial length of helices with large helix pitch angles turns to be

$$
L_{0}=\pi D n \tan \alpha
$$

The helix pitch angle at the buckled configuration, $\alpha_{c r}$, is then computed by the following.

$$
\alpha_{c r}=\tan ^{-1}\left(\frac{L_{o}-\delta_{c r}}{\pi D n}\right)
$$


As stated above, for a given free axial length, $L_{0}$, a helical compression spring has a tendency to buckle when the tip deflection, $\delta$, becomes too large. Buckling can, therefore, be prevented by limiting the tip deflection of the spring or the free length of the spring.

\section{Validation with both Theoretical and Experimental Results}

In this section, mainly four examples, which consist of carefully selected benchmark solutions for nineteen test springs in the available literature, are to be discussed to validate the present results and to show the effectiveness of the present formula.

Geometrical and material properties of the test springs in the first example ( $E=210 G P a$, $v=0.3$, fixed-fixed) are given in Table 1. Comparison of the critical dimensionless buckling loads of the first example is presented in Table 2. Corresponding dimensionless critical buckling load values are also presented in parenthesis in Table 2.

Tab. 1 Geometric sizes of the test springs of the first example

\begin{tabular}{crrrrrrr}
\hline \hline $\begin{array}{c}\text { Spring } \\
\text { number }\end{array}$ & $\begin{array}{c}L_{o} \\
(\mathrm{~mm})\end{array}$ & $\begin{array}{c}D \\
(\mathrm{~mm})\end{array}$ & $\frac{L_{0}}{D}$ & $\begin{array}{c}d \\
(\mathrm{~mm})\end{array}$ & $C$ & $n$ & $\alpha\left(^{\circ}\right)$ \\
\hline 1 & 240 & 40 & 6 & 8 & 5 & 6 & 17.657 \\
2 & 720 & 100 & 7.2 & 25 & 4 & 15 & 8.687 \\
3 & 90 & 10 & 9 & 4 & 2.5 & 15 & 10.812 \\
4 & 120 & 10 & 12 & 2 & 5 & 20 & 10.812 \\
5 & 240 & 20 & 12 & 4 & 5 & 6 & 32.482 \\
6 & 100 & 25 & 4 & 5 & 5 & 6 & 11.98 \\
7 & 50 & 10 & 5 & 2 & 5 & 10 & 9.04 \\
\hline \hline
\end{tabular}

From Table 2, a good harmony among the elementary, the reported and the present results is observed for the first four test springs. However, when the fifth test spring of helix pitch angle of $32.482^{\circ}$ is considered, the elementary theory fails to truly compute the buckling loads as stated previously in $[48,52-53,55]$. The relative error between the elementary theory and the results in [53] may be computed as $13 \%$ for the fifth spring. Another point is that, in Table 2 , İbrikçi et al. [55] found the maximum relative error as $(-0.43 \%)$ for the third test spring having $C=2.5$ which falls into the extended range of the spring index (Table 1). This is an indication of the efficiency of the present formula.

From Table 2, for the test spring numbered six, the critical buckling load reads $P_{c r}=38171.395(N)$. The corresponding tip deflection and buckling helix angle may be computed as $\delta_{c r}=0.586377 \mathrm{~m}=586.377 \mathrm{~mm}$ and $\alpha_{c r}=-45.91^{\circ}$, respectively. Since these results are not plausible $\left(\delta_{c r} / L_{o}=5.86, L_{o}-L_{s}=100-30=70 \mathrm{~mm}\right)$, it is decided that the spring will not be buckled under this force. It may be similarly proved that the seventh test spring will also not be buckled due to $P_{c r}=784.619(N)$ cannot be reached.

The material and geometrical properties of the second example are: $C=D / d=6$, $E=206.84 G P a, v=0.3, d=1 \mathrm{~mm}, k_{T}=1.1$, fixed-fixed. The results for the two test springs are presented in Table 3. In Table 3, Y1ldırım [56] obtained buckling loads under two assumptions: by considering the effects of i) just torsional moment (Eq. 2), $\delta=64 n P R^{3} /\left(G d^{4}\right)$ , ii) torsional and bending moments plus shearing and axial forces. He [56] found that the relative difference between two results was about $21 \%$ for the first open-coiled test spring having larger helix pitch angle while it is negligible for the second closely-coiled one having 
small helix pitch angle. From the results of the first test spring, it is once more revealed that Haringx's results are poor with the springs having large pitch helix angles together with especially relatively small spring index.

Tab. 2 Comparison of the critical buckling loads for the first example

\begin{tabular}{|c|c|c|c|c|c|c|c|}
\hline \multirow{2}{*}{$\begin{array}{l}\text { spring } \\
\text { number }\end{array}$} & \multicolumn{6}{|c|}{$P_{c r}(N)$} & \multirow{2}{*}{$\frac{\alpha_{c r}\left({ }^{o}\right)}{[55]}$} \\
\hline & [48] & [52] & [6] & [53] & [55] & Present & \\
\hline \multirow[t]{2}{*}{1} & 10116.8 & 11505.3 & 10777.2 & 10744.34 & 10725.17 & 10776.43 & 10.1800 \\
\hline & $(0.1061)^{\mathrm{d}}$ & $(0.1200)^{\mathrm{d}}$ & $(0.1124)^{\mathrm{d}}$ & $(0.1121)^{\mathrm{d}}$ & $(0.1119)^{\mathrm{d}}$ & $(0.112435)^{\mathrm{d}}$ & \\
\hline \multirow[t]{2}{*}{2} & 48182.9 & 48491.6 & 48343.3 & 48319.864 & 48162.470 & 48313.714 & 6.4042 \\
\hline & $(0.0306)^{\mathrm{d}}$ & $(0.0308)^{\mathrm{d}}$ & $(0.0307)^{\mathrm{d}}$ & $(0.0307)^{\mathrm{d}}$ & $(0.0306)^{d}$ & $(0.030696)^{\mathrm{d}}$ & \\
\hline \multirow[t]{2}{*}{3} & 2345.3 & 2351.29 & 2356.51 & 2342.390 & 2332.206 & 2332.902 & 9.0519 \\
\hline & $(0.0230)^{\mathrm{d}}$ & $(0.0231)^{\mathrm{d}}$ & $(0.0231)^{\mathrm{d}}$ & $(0.0230)^{\mathrm{d}}$ & $(0.0229)^{\mathrm{d}}$ & $(0.022907) \mathrm{d}$ & \\
\hline \multirow[t]{2}{*}{4} & 77.95 & 78.46 & 79.06 & 78.292 & 78.292 & 78.186 & 9.9315 \\
\hline & $(0.0122)^{\mathrm{d}}$ & $(0.0123)^{\mathrm{d}}$ & $(0.0124)^{\mathrm{d}}$ & $(0.0123)^{\mathrm{d}}$ & $(0.0123)^{\mathrm{d}}$ & $(0.012283)^{\mathrm{d}}$ & \\
\hline \multirow[t]{2}{*}{5} & 906.9 & 984.01 & 1054.21 & 935.170 & 937.048 & 938.848 & 30.3133 \\
\hline & $(0.0483)^{\mathrm{d}}$ & $(0.0524)^{\mathrm{d}}$ & $(0.0561)^{\mathrm{d}}$ & $(0.0498)^{\mathrm{d}}$ & $(0.0499)^{\mathrm{d}}$ & $(0.049996)^{\mathrm{d}}$ & \\
\hline 6 & $--^{\mathrm{a}}$ & -- b & -- b & $--^{\mathrm{c}}$ & $--^{\mathrm{c}}$ & $\begin{array}{r}38171.395 \\
(0.967421)^{\mathrm{d}}\end{array}$ & $--^{c}$ \\
\hline 7 & $--^{\mathrm{a}}$ & $--^{b}$ & $--^{\mathrm{b}}$ & $--^{c}$ & $--^{c}$ & $\begin{array}{r}784.619 \\
(0.12194)^{\mathrm{d}}\end{array}$ & $--^{c}$ \\
\hline
\end{tabular}

${ }^{a}$ no convergent solution

${ }^{b}$ will not buckle (decided from the charts)

${ }^{c}$ not studied

${ }^{d}$ dimensionless critical buckling load

Tab. 3 Buckling loads of the second example

\begin{tabular}{|c|c|c|c|c|c|c|}
\hline \multirow[b]{2}{*}{$n$} & \multirow[b]{2}{*}{$\alpha\left(^{o}\right)$} & \multirow[b]{2}{*}{$L_{o} / D$} & \multicolumn{2}{|c|}{$P_{c r}(N)[56]$} & \multicolumn{2}{|c|}{ Present Formula } \\
\hline & & & Eq. (2) & Eq. (9) & $\bar{P}_{c r}$ & $P_{c r}(N)$ \\
\hline 5 & 18.9717 & 5.4 & 156.292 & 197.149 & 0.187224 & 188.891464 \\
\hline 30 & 7.6147 & 12.6 & 8.43780 & 8.45764 & 0.007681 & 8.513447 \\
\hline
\end{tabular}

The material and geometrical properties of the third example are: $C=D / d=10, n=5$, $E=206.84 G P a, v=0.3, d=1 \mathrm{~mm}, k_{T}=1.1$, fixed-fixed, $\alpha=32.4816366^{\circ}, L_{o} / D=10$. Critical buckling loads and corresponding helix pitch angles together with the ratio of the critical deflection to the helix axial free length are presented in Table 4 in a comparative manner. Since the spring has also a large spring index, a significant deviation from the elementary theory does not occur for this test spring having a large pitch angle.

Table 4 also states that if the whole effects of the stress resultants is concerned by Eq. (9), one may reach higher critical buckling loads than the elementary theory. Critical buckling loads computed by Haringx's [6] formula which considers just the effect of the torsional moment without helix pitch angle mostly fell in the safe region in the design. 
Tab. 4 Critical buckling loads of the third example

[54,58] (in a dynamic manner) [53] (in a static manner)

Present Formula

\begin{tabular}{ccccccccc} 
& $P_{c r}(N)$ & $\left.\alpha_{c r}{ }^{o}\right)$ & $\delta_{c r} / L_{o}(\%)$ & $P_{c r}(N)$ & $\left.\alpha_{c r}{ }^{o}\right)$ & $\delta_{c r} / L_{o}(\%)$ & $P_{c r}(-)$ & $P_{c r}(N)$ \\
\cline { 2 - 8 } Eq. (9) & 21.283 & 29.287 & 11.9 & 21.299 & 29.271 & 11.96 & 0.07406 & 21.404 \\
$\delta=64 n P R^{3} \cos \alpha /\left(G d^{4}\right)$ & 20.4 & 30.17 & 8.7 & -- & -- & -- & -- & - \\
$\delta=64 n P R^{3} /\left(G d^{4}\right)=$ & 20.9 & 29.66 & 10.6 & -- & -- & -- & -- & - \\
Eq. (2) & & & & & & & & \\
\hline \hline
\end{tabular}

As a final example, nine test springs made of ASTM A323 Type 304(SS) [38-39] are considered. The common properties of these springs are: $D=18 \mathrm{~mm}, d=2 \mathrm{~mm}, C=9$, $E=193 \mathrm{GPa}, G=70.3 \mathrm{GPa}$. The other specifications of the springs and their buckling loads which are determined numerically and experimentally are shown in Table 5.

Tab. 5 Experimental and theoretical critical buckling loads of the fourth example

\begin{tabular}{clllllllll}
\hline \hline & & \multicolumn{9}{c}{$\begin{array}{l}\text { Experimental } \\
{[44]}\end{array}$} & \multicolumn{3}{l}{$\begin{array}{l}\text { Theoretical } \\
{[44]}\end{array}$} \\
\cline { 5 - 10 } $\begin{array}{l}\text { Spring } \\
\text { no }\end{array}$ & $L_{o} / D$ & $\alpha\left(^{\circ}\right)$ & $n$ & $\begin{array}{l}P_{c r} \\
(\mathrm{~N})\end{array}$ & $\begin{array}{l}\delta_{c r} \\
(\mathrm{~mm})\end{array}$ & $\begin{array}{l}P_{c r} \\
(\mathrm{~N})\end{array}$ & $\begin{array}{l}\delta_{c r} \\
(\mathrm{~mm})\end{array}$ & $\begin{array}{l}P_{c r} \\
(\mathrm{~N})\end{array}$ & $\begin{array}{l}\delta_{c r} \\
(\mathrm{~mm})\end{array}$ \\
\hline 1 & 5.6 & 2.22 & 20 & 63.21 & 45.34 & 68.51 & 56.30 & 69.35 & 54.97 \\
2 & 5.83 & 2.82 & 20 & 62.50 & 44.28 & 58.95 & 49.14 & 61.16 & 48.49 \\
3 & 7.0 & 3.68 & 25 & 40.30 & 32.59 & 34.00 & 32.03 & 35.21 & 34.88 \\
4 & 8.17 & 4.60 & 25 & 32.10 & 24.48 & 26.37 & 28.22 & 28.36 & 28.12 \\
5 & 9.72 & 5.91 & 26 & 29.34 & 22.80 & 21.18 & 22.75 & 21.90 & 22.69 \\
6 & 10.6 & 6.59 & 26 & 27.12 & 18.29 & 18.99 & 20.71 & 19.86 & 20.52 \\
7 & 11.1 & 6.98 & 27 & 23.40 & 18.70 & 17.63 & 19.40 & 18.03 & 19.35 \\
8 & 12.8 & 8.24 & 27 & 19.20 & 16.40 & 15.17 & 16.56 & 15.41 & 16.56 \\
9 & 14 & 9.14 & 28 & 16.40 & 13.30 & 12.85 & 15.12 & 13.38 & 14.94 \\
\hline \hline
\end{tabular}

For those nine springs, present applied force and corresponding deflections are presented in Table 6. Table 6 also includes Patil et. al.'s [43, 44] experimental deflection values in parenthesis.

In Table 5, the present and Patil et al.'s [43-44] theoretical results are closer to each other than their experimental values. To achieve a better comparison of the theoretical and experimental values, load-deflection curves from the present results and experimental ones together with theoretically and experimentally determined buckling loads are all illustrated in the same figure for the nine test springs considered (Fig. 4). From Fig. 4 the followings may be concluded:

- The specifications of the test springs were indeed chosen within the range of the elementary theory by Patil et al. [43, 44]. Despite this, the experimental results have some errors especially for springs having around $6^{\circ}-10^{\circ}$ helix pitch angles and when the loads are increased. The maximum relative error may be reached around $40 \%$ in Patil et al.'s $[43,44]$ theoretical and experimental results.

- Buckling loads obtained by the present formula fall on the linear load-deflection line obtained by Yildırım's [31] deflection formula in Eq. (9). This may be assumed as the other verification of the present formula. 
Tab. 6 The present applied force and corresponding deflections for the fourth example

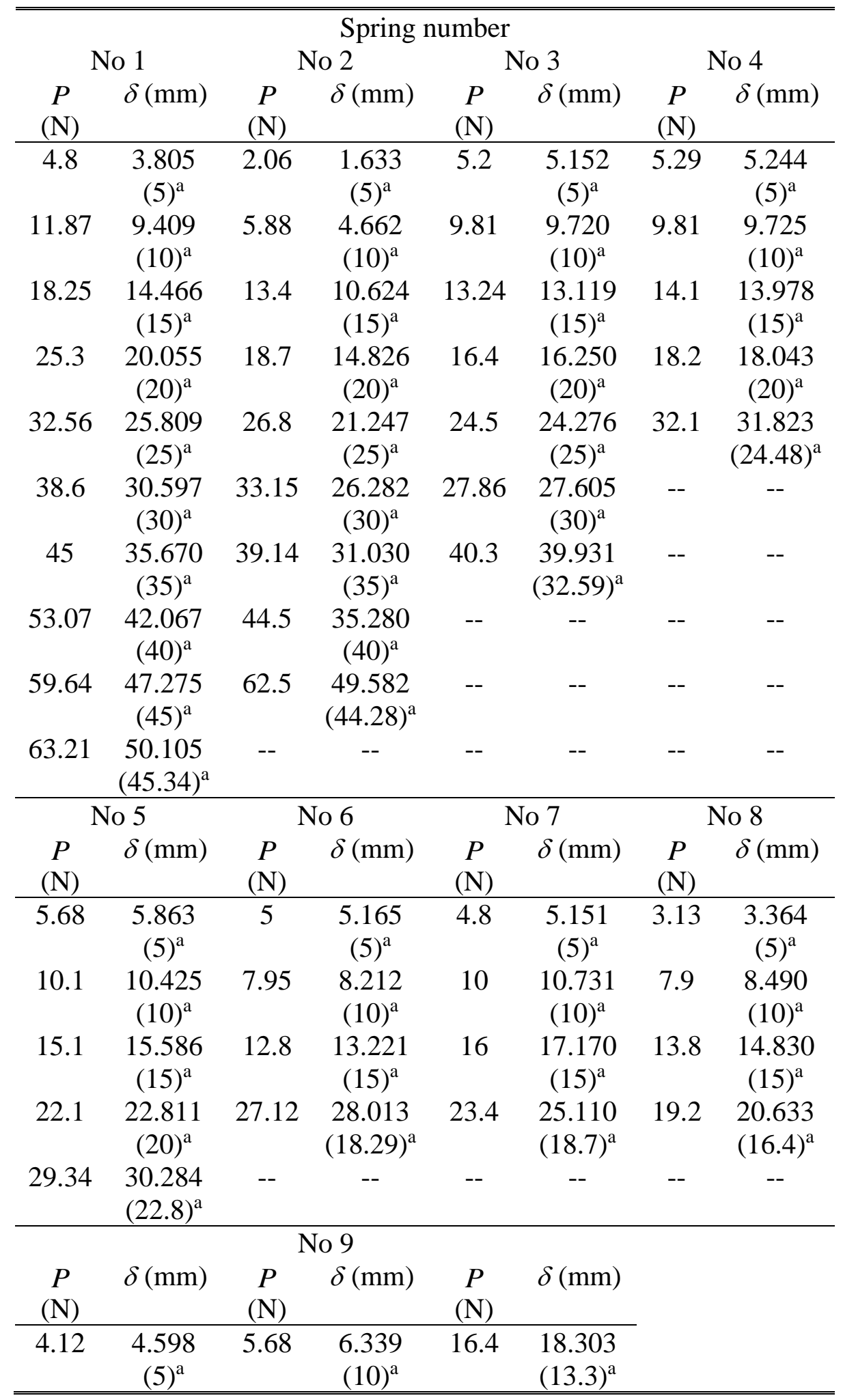

${ }^{\text {a} P a t i l ~ e t . ~ a l . ~}[43,44] /$ experimental

As stated above, there is a good harmony between Patil et al.'s [43-44] theoretical and the present buckling loads. 

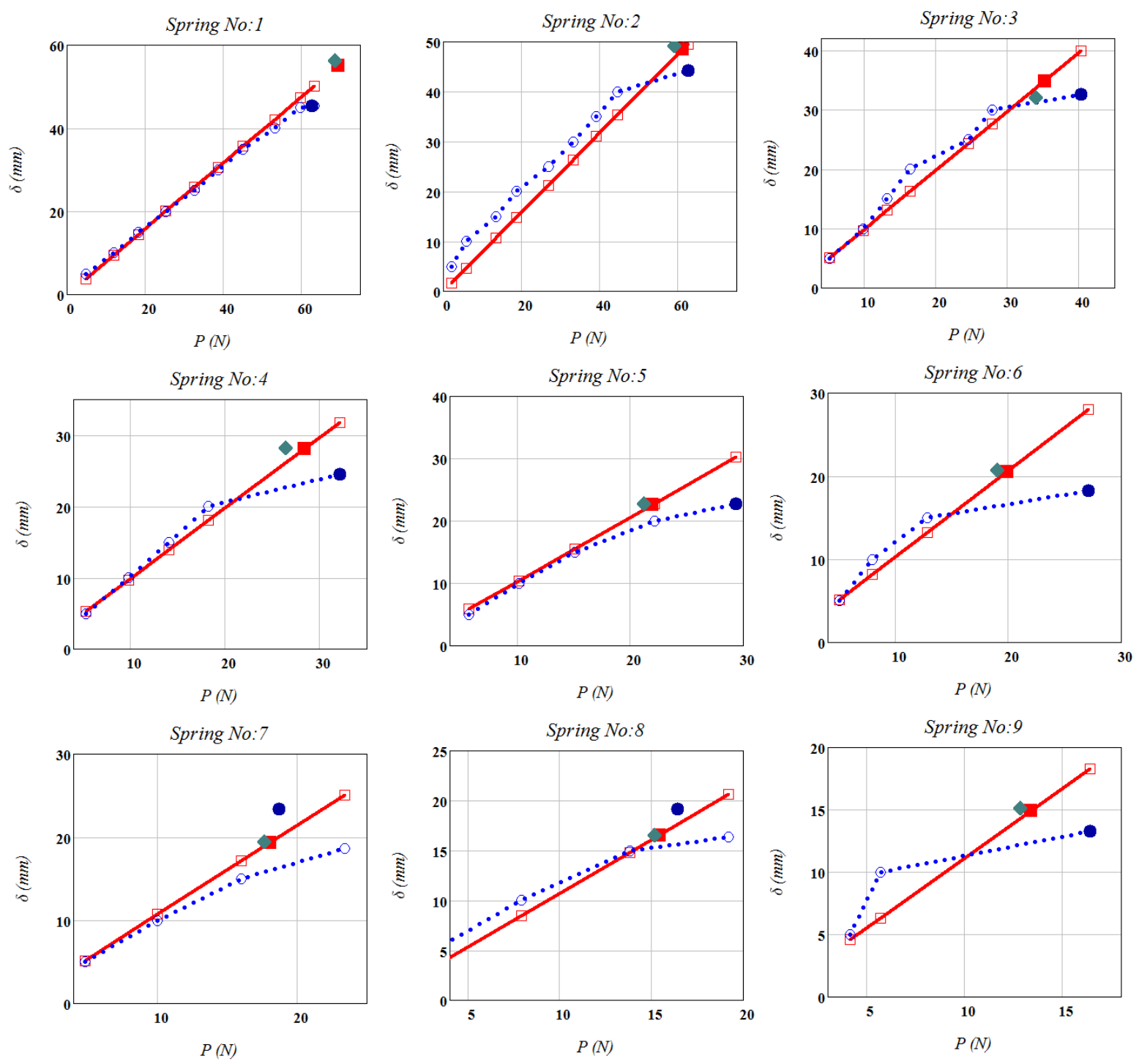

브는 Present (load-deflection)/(Eq. 9)

2. Patil et. al. [44] (load-deflection)/Experimental Present Buckling Load/(Eq. 6)/ANN

- Patil et al. [44] Buckling Load /Experimental

Patil et al. [44] Buckling Load/Theoretical

Fig. 4 Load-deflection curves and buckling loads

\section{$5 \quad$ Parameters Affecting the Buckling Loads}

The present buckling formula apparently considers three parameters, namely the spring index, $C=D / d$, the number of active turns, $n$, and the ratio of $L_{o} / D$. In this section the effects of those parameters on the dimensionless critical buckling loads are to be discussed.

Figure 5 shows the effect of the spring index on the critical buckling loads for $n=10$. The effect of the spring index increases when the ratio of $L_{o} / D$ decreases. This effect becomes maximum for the smallest value of the spring index, that is for $C=4$. As may be guessed, as $L_{o} / D$ increases the deviations in the results of the springs having different spring indexes become to disappear. 

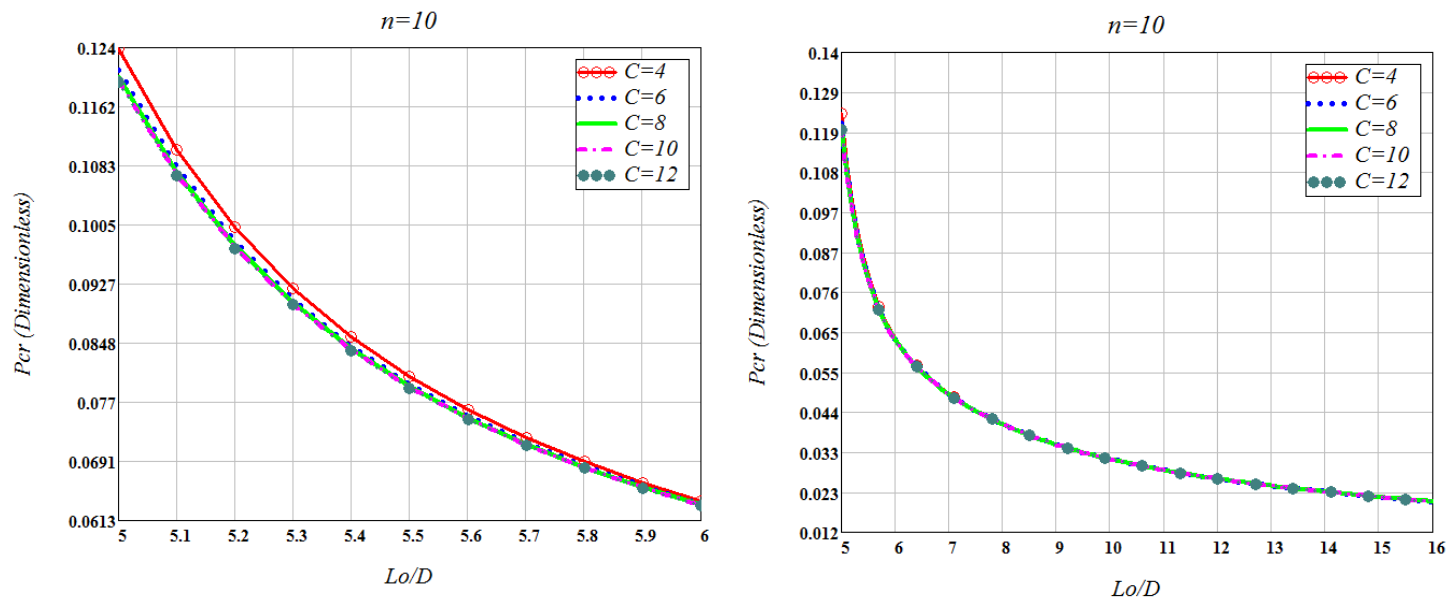

Fig. 5 Effect of the spring index on the buckling loads

Figure 6 illustrates the effect of the total number of active turns on the critical buckling loads for $C=4$. The effect of the number of active turns decreases with increasing $L_{o} / D$ ratios. The dimensionless critical buckling loads decrease with increasing number of active turns. For the given values of $L_{o} / D$ and $C$, reducing the number of active turns may be an option to increase the buckling loads since the deflection becomes smaller.

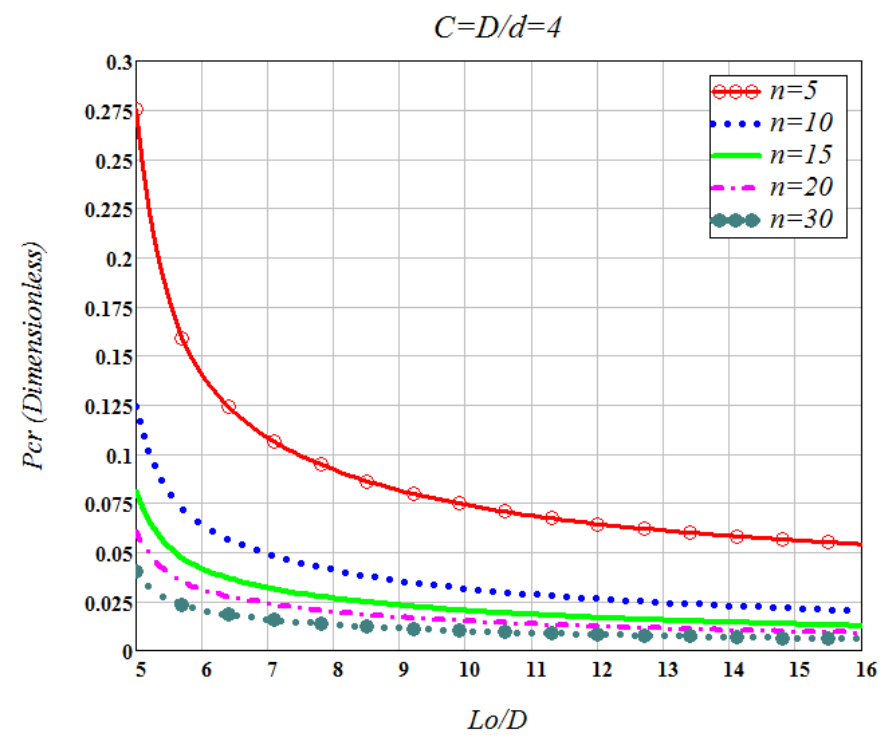

Fig. 6 Effect of the number of active turns on the buckling loads

Effect of $L_{o} / D$ ratios on the buckling loads are shown in Fig. (7) for $C=4$. Smaller $L_{o} / D$ ratios offer higher buckling loads for given $n$ and $C$ values. Critical buckling loads decrease with increasing number of active turns for all values of $L_{o} / D$ values.

\section{CONCLUSION}

Buckling of helical springs is still an issue which deserves much attaching a great importance by investigators. The responses of the existing elementary buckling formulas are poor for the springs with large pitch helix angles together with relatively small spring index. They may be used safely for closely-coiled springs in which the helix pitch angle is small and the spring index is relatively large.

In the present study an accurate and effective buckling formula is offered to additionally consider the effects of all the stress resultants on the buckled state together with the axial and 
shear deformation. The proposed formula may be freely and safely used in a wide range of the total number of active turns, the ratio of the free axial length to the mean helix diameter, and the spring index. The verification of the present formula was performed with the reported experimental and theoretical buckling loads.

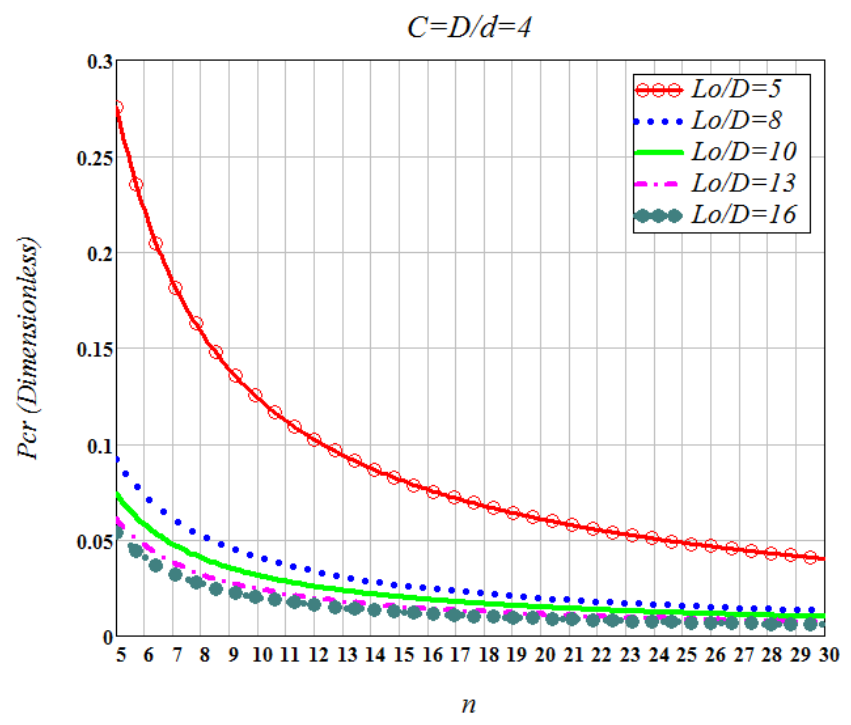

Fig. 7 Effect of $L_{o} / D$ ratios on the buckling loads

\section{ACKNOWLEDGEMENTS}

The author is grateful to the referees for the time spent and their meticulous reviews.

\section{REFERENCES}

[1] Tondl. Dynamic Absorber for a Suspended Platform. Journal of Mechanical Engineering - Strojnícky časopis 1998 (49), No. 5, 307-318.

[2] M. Bouazara. Optimization of the Suspension Parameters and Tire Forces Analysis on a Vehicle Model Using an Analytical Approach. Journal of Mechanical Engineering Strojnicky časopis 2005 (56), No. 5, 257-272.

[3] M. Musil, J. Úradníček. Numerical Comparison of Car Suspension Control Strategies Employing a Continuous Semiphysical MR Damper Model. Journal of Mechanical Engineering - Strojnícky časopis 2009 (60), No. 5-6, 243-256.

[4] K. Rajeswari, P. Lakshmi. A Pso-Tuning of Fuzzy Logic Controller for Vehicle Suspension System. Journal of Mechanical Engineering - Strojnícky časopis 2010 (61), No. 4, 215-232

[5] C. Bendigeri. Coupled Field Analysis of Amplified Piezo Actuator by Finite Element Method. Journal of Mechanical Engineering - Strojnícky časopis 2011 (62), No. 3, 143158.

[6] J. A. Haringx. On Highly Compressible Helical Springs and Rubber Rods, and Their Application for Vibration-Free Mountings. Philips Research Reports 1949 (4), 49-80.

[7] C. J. Ancker, J. N. Goodier. Pitch and Curvature Corrections for Helical Springs. J Appl Mech 1958 (25), 466-470.

[8] C. J. Ancker, J. N. Goodier. Theory of Pitch and Curvature Corrections for the Helical Springs-I (Tension). Trans ASME- J Appl Mech 1958 (25), 471-483. 
[9] C. J. Ancker, J. N. Goodier. Theory of Pitch and Curvature Corrections for the Helical Springs-II (Torsion). Trans ASME- J Appl Mech 1958 (25), 484-495.

[10] A. M. Wahl. Mechanical Springs. 2nd ed., McGraw-Hill, New York, 1963.

[11] G. A. Costello. Radial Expansion of Impacted Helical Springs. J Appl Mech ASME 1975 (42), 789-792.

[12] Y. Lin, A. P. Pisano. The Differential Geometry of the General Helix as Applied to Mechanical Springs. J Appl Mech ASME 1988 (55), 831-836.

[13] Y. Lin, A. P. Pisano. Three-Dimensional Dynamic Simulation of Helical Compression Springs. J. Mech. Des 1990 (112), No. 4, 529-537.

[14] M. H. Omurtag, A. Y. Aköz. The Mixed finite Element Solution of Helical Beams with Variable Cross- Section Under Arbitrary Loading. Comput Struct 1992 (43), No. 2, 325331.

[15] K. Nagaya, Y. Hirata, T. Tsurumi, S. Takeda, K. Nagai, K. Tanifuji. Design Formulae for Elliptical Cross-Section Helical Springs. J. Mech. Des 1992 (114), No. 4, 667-669. doi: $10.1115 / 1.2917058$

[16] V. Haktanır, E. Kıral, Statical Analysis of Elastically and Continuously Supported Helicoidal Structures by the Transfer and Stiffness Matrix Methods. Comput Struct 1993 (49), No. 4, 663-677.

[17] V. Haktanır. The Complementary Functions Method for the Element Stiffness Matrix of Arbitrary Spatial Bars of Helicoidal Axes. Int J Numer Methods Eng 1995 (389, No. 6, 1031-1056.

[18] V. Y1ldırım. Governing Equations of Initially Twisted Elastic Space Rods Made of Laminated Composite Materials. Int J Eng Sci 1999 (37), 1007-1035.

[19] W. G. Jiang, J. L. Henshall. A Novel finite Element Model for Helical Springs. Finite Elem Anal Des 2000 (35), 363-377.

[20] J. M. Selig, X., Ding. Structure of the Spatial Stiffness Matrix. Int J Robot Autom 2002 (17), No. 1, 1-16.

[21] X. Ding, J. M. Selig. On the Compliance of Coiled Springs. Int J Mech Sci 2004 (46), 703-727.

[22] F. Dammak, M. Taktak, S. Abid, A. Dhieb, M.Haddar. Finite Element Method for the Stress Analysis of Isotropic Cylindrical Helical Spring. Eur J Mech A Solids 2005 (24), No. 6, 1068-1078.

[23] M. Taktak, F. Dammak, S. Abid, M. Haddar. A Mixed-Hybrid Finite Element for ThreeDimensional Isotropic Helical Beam Analysis. Int J Mech Sci 2005 (47), No. 2, 209-229.

[24] A. M. Yu, X. G. Yang, G. H. Nie. Generalized Coordinate for Warping of Naturally Curved and Twisted Beams with General Cross-Sectional Shapes. Int J Solids Struct 2006 (43), 2853-2867.

[25] W. G. Jiang, M. K. Warby, J. L. Henshall. Statically Indeterminate Contacts in Axially Loaded Wire Strand. Eur J Mech A/Solids 2008 (27), 69-78.

[26] C. L. Dym. Consistent Derivations of Spring Rates for Helical Springs. ASME J Mech Des 2009 (131), No. 7, 0710041-5.

[27] R. Mirzaeifar, R. DesRoches, A. A. Yavari. Combined Analytical, Numerical, and Experimental Study of Shape-Memory-Alloy Helical Springs. Int J Solids Struct 2011 (48), 611-624. 
[28] A. Frikha, P. Cartraud, F. Treyssede. Mechanical Modeling of Helical Structures Accounting for Translational Invariance. Part I: Static Behavior. Int J Solids Struct 2013 (50), 1373-1382.

[29] K. Nikolaos, K. Gerald. Mechanical Response of A Helical Body to Axial, Torsional and Radial Strain. Int J Mech Sci 2015 (94-95), 260-265.

[30] M. Paredes. Enhanced Formulae for Determining both Free Length and Rate of Cylindrical Compression Springs. J Mech Des 2016 (138), No. 2, 021404-5[15](6 p.).

[31] V. Yildirım. Exact determination of the global tip deflection of both close-coiled and open-coiled cylindrical helical compression springs having arbitrary doubly-symmetric cross-sections. Int J Mech Sci 2016 (115-116), 280-298.

[32] M. Ermis, M. Y1lmaz, N. Eratl1, M. H. Omurtag. Static and Dynamic Analysis of NonCircular Helicoidal Bars with Cruciform Cross-Sections via Mixed FEM. The 2016 World Congress on The 2016 Structures Congress (Structures16), Jeju Island, Korea, August 28-September 1, 2016, 10 pages.

[33] A. N. Chaudhury, A. Ghosh, K. Banerjee, A. Mondal. Analysis of Prismatic Springs of Non-circular Coil Shape Using Finite Element Method. Chapter CAD/CAM, Robotics and Factories of the Future, Part of the series Lecture Notes in Mechanical Engineering, Springer, 2016, 243-251.

[34] N. Karathanasopoulos, H. Reda, J. F. Ganghoffer. Finite Element Modeling of the Elastoplastic Axial-Torsional Response of Helical Constructions to Traction Loads. Int J Mech Sci 2017 (133), 368-375.

[35] M. Gzal, M. Groper, O. Gendelman. Analytical, Experimental and Finite Element Analysis of Elliptical Cross-Section Helical Spring ith Small Helix Angle under Static Load. Int J Mech Sci 2017 (130), 476-486.

[36] A. N. Chaudhury, D. Datta. Analysis of Prismatic Springs of Non-Circular Coil Shape and Non-Prismatic Springs of Circular Coils Shape by Analytical and Finite Element Methods. Journal of Computational Design and Engineering 2017 (4), No. 3, 178-191.

[37] J. Ekanthappa, S. Basavarajappa, G.S. Shiva Shankar. Fabrication \& Experimentation of the Glass-Epoxy Helical Spring Reinforced with Graphite Powder. Materials Today: Proceedings, AMMMT 2016 (4), No. 10, 11034-11038.

[38] V. Balambica, V. Deepak. Static Analysis of Slotted Springs. International Conference on Automatic Control and Dynamic Optimization Techniques, ICACDOT 201613, March 2017, Article no 7877627, 2017, 455-459.

[39] A. H. Jebur. A Study of the Effect of Parameters on the Stress in Helical Spring Wire. AlQadisiyah Journal for Engineering Science 2017 (10), No. 2, 133-146.

[40] Z. Y. Xiong, R. X. Song, R. Wu, Z. X. Kang, H. J. Zhang, Q. Liu Study on Rigidity and Strength of a New Type of Helical Composite Spring. Mechanics and Materials Science 2017, 163-174. doi.org/10.1142/9789813228177_0019.

[41] A. M. Choube. Finite Element Analysis of Helical Spring in Monosuspension System. Int J Eng Sci, IJESC 2016. doi 10.4010/2016.1124

[42] V. Kobelev. Durability of Springs, Springer, Cham DOI 10.1007/978-3-319-58478-2_3 2018, 1-270.

[43] R. V. Patil, P. R. Reddy, P. Laxminarayana. Buckling Analysis of Straight Helical Compression Springs Made of ASTM A229 Gr-II, ASTM A313 Materials (Type 304 \& 316). Int J Eng Res Technol (IJERT) 2013 (2), No. 6, 978-986. 
[44] R. V. Patil, P. R. Reddy, P. Laxminarayana. Comparison of Cylindrical and Conical Helical Springs for Their Buckling Load and Deflection. Int J Adv Sci Technol 2014 (73), 33-50. doi.org/10.14257/ijast.2014.73.03

[45] D. Pearson. The Transfer Matrix Method for The Vibration Of Compressed Helical Springs. Int J Mech Eng Sci 1982 (24), 163-171.

[46] Y. Lin, A. P. Pisano. General Dynamic Equations of Helical Springs with Static Solution and Experimental Verification J Appl Mech 1987 (54), 910-917.

[47] B. Tabarrok, Y. Xiong. On the Buckling Equations for Spatial Rods. Int J Mech Sci 1989 (31), No. 3, 179-192.

[48] B. Tabarrok, Y. Xiong. A Spatially Curved and Twisted Rod Element for Buckling Analysis. Int J Solids Struct 1992 (29), No. 23, 3011-3023.

[49] Y. Xiong, B. Tabarrok. A Finite Element Model for the Vibration of Spatial Rods under Various Applied Loads. Int J Mech Sci 1992 (34), No. 1, 41-51.

[50] L. E. Becker, W. L. Cleghorn. On the Buckling of Helical Compression Springs. Int J Mech Sci 1992 (34), No. 4, 275-282.

[51] L. E. Becker, W. L. Cleghorn. The Buckling Behavior of Rectangular-Bar Helical Compression Springs. J Appl Mech 1994 (61), 491-493.

[52] G. G. Chassie, L. E. Becker, W. L. Cleghorn. On the Buckling of Helical Springs under Combined Compression and Torsion. Int J Mech Sci 1997 (39), No. 6, 697-704.

[53] V. Yildirim. Buckling and Free Vibration Problems of Helical Compression Springs with Pre-Load - A Software Program and Design Charts. TUBITAK Report, No. 106M307, 2009.

[54] V. Yıldırım. Numerical Buckling Analysis of Cylindrical Helical Coil Springs in a Dynamic Manner. Int J Eng Appl Sci (IJEAS) 2009 (1), No. 1, 20-32. http://dergipark.gov.tr/download/article-file/217599

[55] T. Ibrikçi, S. Saçma, V. Yıldırım, T. Koca. Application of Artificial Neural Networks in the Prediction of Critical Buckling Loads of Helical Compression Springs. Stroj-Vestnik - J Mech Eng 2010 (56), No. 6, 409-417.

[56] V. Y1ldirım. On the Linearized Disturbance Dynamic Equations for Buckling and Free Vibration of Cylindrical Helical Coil Springs under Combined Compression and Torsion. Meccanica 2012 (47), No. 4, 1015-1033.

[57] I. Kacar, V. Yildirim, Free vibration/buckling analyses of noncylindrical initially compressed helical composite springs, Mech Based Design Struct Mach 2016 (44), No. 4, 340-353, 10.1080/15397734.2015.1066687

[58] V. Y1ldırım. Axial static load dependence free vibration analysis of helical springs based on the theory of spatially curved bars. Latin American Journal of Solids and Structures 2016 (13), 2852-2875.

[59] G. R. Cowper. On the Accuracy of Timoshenko's Beam Theory. J Eng Mech Div ASCE 1968 (94), 1447-1453 EM6.

[60] M. İnan. Strength of Materials. Birsen Company, Istanbul (in Turkish), 1967. 